\title{
Depois do fim: as rasuras de uma portuguesa em terra angolana - uma leitura de Teoria geral do esquecimento, de José Eduardo Agualusa
}

\author{
After the end: traces of a Portuguese in Angola - a reading of \\ Teoria geral do esquecimento, by José Eduardo Agualusa
}

PAULO RICARDO KRALIK ANGELINI

Pontificia Universidade Católica do Rio Grande do Sul - Porto Alegre - Rio Grande do Sul - Brasil at

Resumo: A partir de alguns conceitos teóricos trabalhados por Zygmunt Bauman, Stuart Hall, Eduardo Lourenço e Inocência Mata, pretende-se acompanhar o apagamento da identidade de uma portuguesa em Angola. Durante o processo de descolonização, Ludovica fica abandonada à própria sorte e refugia-se em um apartamento, fechando as paredes e escondendo-se do mundo. É lá, num espaço à parte, reclusa, distante de uma Luanda fervilhante, que ela perde seus contornos lusitanos, vendo nascer uma angolanidade imprevista.

Palavras-chave: Descolonização; Identidade; José Eduardo Agualusa

\begin{abstract}
Based on concepts over identity explored by theorists such as Zygmunt Bauman, Stuart Hall, Eduardo Lourenço and Inocência Mata, we intend to follow the fading of national distinctiveness of a Portuguese living in Angola. During the process of decolonization, Ludovica is abandoned to her fate and takes refuge in her own apartment, closing walls and hiding from the world. In this secluded space, as a recluse, far from buzzing Luanda, she loses her Portuguese identity.
\end{abstract}

Keywords: Decolonization; Identity; José Eduardo Agualusa

\author{
eu ostra cismo \\ cá com minhas pérolas \\ cacos no abismo \\ (AGUALUSA, 2012:85)
}

"Abre a porta, mamã. A gente só quer o que nos pertence. Vocês nos roubaram durante quinhentos anos. Viemos buscar o que é nosso" (AGUALUSA, 2012:24). ${ }^{1}$ Trancada em seu apartamento, a portuguesa Ludovica protege-se como pode. E como sabe: ensimesmando-se. Virando para dentro de si própria. Defende a sua vida e o seu espaço, embarricada que está em uma casa a servir de escudo contra uma Angola em ebulição. Quando estoura a revolução dos cravos em Portugal, o mundo de Ludovica, alicerçado a milhares de quilômetros de Lisboa, também sofre abalos impactantes. Personagem-tartaruga, Ludovica sempre detestara espaços abertos, tinha pânico

\footnotetext{
1 A partir de agora, todas as referências à obra consultada (Lisboa: D.
} Quixote, 2012) serão assinaladas apenas com o número da página. do céu, e "muito pequena, seis, sete anos, recusava-se a ir para a escola sem a proteção de um guarda-chuva negro, enorme, fosse qual fosse o estado do tempo" (13).

É essa mulher que se reveste de cascas a protagonista de Teoria geral do esquecimento, obra de José Eduardo Agualusa, publicada em 2012. Ludovica vive confortavelmente com a irmã, Odete, e com o cunhado, Orlando, empresário angolano de relativo sucesso profissional. Moram em uma cobertura em um edifício pomposo, conhecido como o Prédio dos invejados. Mesmo receosa pela mudança para um lugar com tanto céu - "o céu da África é muito maior do que o nosso, explicou à irmã: esmaga-nos" (15) -, Ludovica acaba por, de algum modo, adaptar-se a um mundo de clausura, evitando as subidas à parte externa da cobertura do apar- 
tamento, cuidando dos afazeres domésticos, e tendo toda a relação com a vida externa a partir da irmã e do cunhado.

Quando explode a revolução de abril, em 1974, os ventos começam a mudar para o trio. Com o passar dos meses, o país africano, encaminhando-se para a independência, de repente parece tornar-se inóspito para quem é branco e português. $\mathrm{O}$ fato histórico, dramatizado por Agualusa, mostra um processo gigantesco de migração. De acordo com a obra História de Angola, de Douglas Wheeler e René Pélissier, dos 330 mil portugueses residentes em abril de 1974, quase 300 mil partiriam em até dois anos. Esta fuga acelerada modificaria o cotidiano angolano, criando uma das pontes aéreas mais disputadas: Luanda-Lisboa.

Ludo testemunha os desentendimentos do casal, já que a irmã quer voltar à Europa por conta do colapso social no qual Luanda começa a mergulhar: "Explodira uma confusão na metrópole. Orlando estava no Dundo. Chegou nessa noite. Fechou-se no quarto com a mulher. Ludo ouviu-os a discutir. Ela queria abandonar Angola o mais rápido possível. Os terroristas, querido, os terroristas...” (15). A esposa portuguesa refere-se aos encaminhamentos da retomada de poder, pró-libertação. Como afirmam Wheeler e Pélissier, o que acontece na Angola de 1975 é algo sem precedentes na África: “a potência colonial entregou o poder, não a um governo ou partido específico, mas sim ao povo de Angola" (WHEELER; PÉLISSIER, 2013:361). De acordo com os autores, os militares portugueses recusaram-se a conceder o poder a qualquer dos movimentos africanos de combate, promovendo uma guerra civil internacionalizada.

Nas discussões, Orlando reconhece a importância do processo de libertação, e vê a situação de outra forma: "Terroristas? Não volte a usar essa palavra na minha casa. (...) Os tais terroristas combateram pela liberdade do meu país. Sou angolano. Não sairei" (16). A querela doméstica reproduz as contradições do período. Sobre esse conturbado processo de descolonização, Eduardo Lourenço discorre, no já clássico texto "Psicanálise mítica do destino português":

Exemplar como revolução metropolitana que derruba quatro décadas de poder autoritário e semitotalitário com flores no cano de espingardas, a revolução de Abril não eclode com o propósito consciente de pôr um termo absoluto à imagem de Portugal colonizador exemplar mas para dentro dela encontrar uma solução à portuguesa, igualmente exemplar de descolonização (LOURENÇO, 2001:49).

O desejo de permanência de Orlando e as inquietações de Odete acabam por abalar o estado de espírito de Ludo. Além disso, a alegria crescente dos angolanos é incomodativa para a personagem, quase uma afronta a sua lusitanidade: "Decorreram dias agitados. Manifestações, greves, comícios. Ludo cerrava as vidraças para evitar que o apartamento se enchesse de gargalhadas do povo nas ruas, estalando no ar como fogo de artifício" (16). A revolta provoca radicalizações, a vontade de Odete em voltar para Portugal aumenta. Deveriam abandonar Angola: "O marido ciciava, em resposta, palavras ríspidas. Elas podiam ir. Os colonos deviam embarcar. Ninguém os queria ali. Um ciclo se cumprira. Começava um tempo novo" (21). Contudo, aos poucos o empresário começa a mudar de ideia sobre a continuidade da família em terras angolanas: "compreendia a necessidade de maior justiça social, mas os comunistas, ameaçando nacionalizar tudo, assustavam-no. Expropriar a propriedade privada. Expulsar os brancos. Partir os dentes à pequena burguesia" (16). Orlando era homem de amor a suas coisas. A seu apartamento luxuoso, invejado. Vaidoso, era homem de amor aos seus dentes.

O pensador Eduardo Lourenço, no texto "A nau de Ícaro ou o fim da emigração", afirma o que parece ser uma grande obviedade: "A emigração supõe que alguma coisa de melhor do que o que se deixa nos espera para nos dar a oportunidade de mudarmos de estado ou de funções" (LOURENÇO, 2001b:45). Esse não foi o caso da emigração de Ludo. A contragosto, partiu para a África, saindo da cidade de Aveiro, por conta do pedido da irmã. A portuguesa nunca se sentiu em casa na colônia. Enquanto na metrópole uma ditadura brutal dava seus últimos suspiros, trazendo o início de novos ares, de uma revolução, como afirma Eduardo Lourenço, mais sonhada do que vivida, Ludo refugiava-se no seio familiar, alienando-se de todo o processo político. Por ser uma revolução tão sonhada, talvez houvesse tanto espaço para a frustração: o real quase nunca se equipara ao material trazido do bojo do campo onírico. Eduardo Lourenço afirma que a grandiosidade portuguesa, construída fora de suas próprias linhas europeias, foi desde sempre uma ficção: "uma grandeza que subterraneamente se sabe uma ficção ou, se se prefere, de uma ficção que se sabe desmedida mas precisa de ser clamada à face do mundo menos para que a ouçam do que para acreditar em si mesma" (LOURENÇO, 2001:26). Há uma dificuldade latente de ser em função do ter sido, um gigantesco ter sido absolutamente fora de si mesmo. Lourenço complementa: "Nós éramos grandes, [...] mas éramos grandes longe, fora de nós, no Oriente de sonho ou num Ocidente impensado ainda" (Ibidem:26).

Essa soberba do português frente ao nativo é percebida nas personagens da obra de Agualusa. Odete, a certa altura, afirma sobre um primo do marido, branco, mas angolano, que ele falava como um preto, que fedia a catinga, empestando a casa sempre que ali entrava. Já a irmã, Ludovica, por exemplo, confessa sentir-se mais próxima dos cães do que daquelas pessoas lá fora. A 
relação do português com o angolano, pois, é tensa e repleta de constrangimentos.

Meses se passam e o prédio dos invejados já está praticamente vazio. As irmãs e o cunhado fazem um estoque de alimentos, produtos de higiene e muitas bebidas. O desabastecimento das cidades provoca o caos. Na obra S.O.S. Angola, a jornalista Rita Garcia reconstrói a vida na capital angolana daquela época:

de um momento para outro, passou a faltar tudo. Os transportes pouco circulavam, ninguém recolhia o lixo e não havia água, nem luz (...). O açúcar, a cerveja e o tabaco desapareceram das prateleiras das lojas que conseguiram manter as portas abertas, e a chegada de produtos frescos à cidade fora afetada pela interrupção da circulação ferroviária e rodoviária (GARCIA, 2011:142).

Na cobertura do prédio dos invejados, Orlando recebe um estoque de vinhos e bebidas da vizinha Rita, que parte para o Rio de Janeiro, não sem antes aconselhá-lo: "Bebam-nas. O importante é que não fique nenhuma para os comunistas festejarem" (17). E assim, um brinde ao desfacelamento do grande sonho imperialista português. Afirma Eduardo Lourenço:

treze anos de guerra colonial, derrocada abrupta desse império, pareciam acontecimentos destinados não só a criar na nossa consciência um traumatismo profundo - análogo ao da perda da independência - mas a um repensamento em profundidade da totalidade da nossa imagem perante nós mesmos e no espelho do mundo (LOURENÇO, 2001: 46).

Contudo, de acordo com o crítico português, a amputação do território teve ares pouco traumáticos aos patrícios, uma vez que "tudo pareceu-nos passar-se como se jamais tivéssemos tido essa famigerada existência imperial e em nada nos afetasse o regresso aos estreitos e morenos muros da pequena casa lusitana" (43). Se para os portugueses civis a vida no país não mudava tanto assim, para o governo português a história era outra. Angola é a pedra no sapato para Portugal. No texto "A descolonização: seu processo e consequências", da obra Portugal em transe, José Medeiros Ferreira afirma que o processo de descolonização de Angola foi o mais complexo e o que trouxe mais consequências internas e externas: "O processo de descolonização de Angola foi também aquele que maiores preocupações gerou em Portugal" (FERREIRA, 2001:57). Com o agravamento da vida na capital angolana, Orlando também decide partir, para a surpresa - e alegria - das portuguesas. A fuga é a única possibilidade. Fugir para um lugar onde muitos nem mais tinham raízes. Como sublinha Lourenço: finalizado o sonho imperialista: chegou a hora de fugir para dentro de casa, de nos barricarmos dentro dela, de construir com constância o país habitável de todos, sem esperar de um eterno lá-fora ou lá-longe a solução que, como no apólogo célebre, está enterrada no nosso exíguo quintal (LOURENÇO, 2001:51).

Nas vésperas da partida, um acontecimento inesperado. O casal sai para uma festa de despedida, sem a irmã. Ludo "esperou por eles, lendo, tricotando, até às duas da manhã. Foi-se deitar inquieta. Dormiu mal. Levantou-se às sete, vestiu um robe, chamou a irmã. Ninguém respondeu. Teve a certeza de que acontecera uma tragédia" (22).

O desaparecimento ficcional dos familiares de Ludo obedece a um fato histórico bastante comum no tempo da descolonização, como afirma um dos entrevistados por Rita Garcia na obra S.O.S. Angola: "Ouvíamos falar de pessoas que desapareciam: umas porque se iam embora, outras porque desapareciam mesmo" (GARCIA, 2011:28). Eram, inclusive, rotineiros os anúncios no jornal Província de Angola de pessoas que procuravam por seus familiares desaparecidos.

Ludo ficará sozinha, pois, por um dia, dois, três meses, quatro, trinta anos. Nunca mais veria a irmã e o cunhado: "Acordei e estava sozinha. Se, dormindo, sonhamos dormir, podemos, despertos, acordar dentro de uma realidade mais lúcida?” (41). Não há lucidez nem realidade onírica capazes de fazer Ludo fugir da própria solidão. Isolada num mundo estranho, com o qual nunca chegou a interagir, a personagem tenta fechar-se ainda mais naquele espaço diminuto, num processo repleto de construções e desconstruções.

Para proteger-se, resolve emparedar-se, criando uma casa-cápsula que resistisse às pressões vindas da rua, das transformações violentas de Angola. Ergue então, uma parede, no corredor do prédio, separando o apartamento do resto do edifício. A professora Helena Buescu chama a atenção, no texto "A casa e a encenação do mundo", para a casa como retraimento do mundo. Ela afirma: "Entrar nela é, também, sair do palco social para penetrar num espaço (que seria) tendencialmente pacificador e regenerador" (BUESCU, 1999:27). Não há aquietação no caso de Ludo. Por mais que imponha barreiras contra o externo, não consegue encontrar um espaço seu de acolhimento. Buescu complementa, na simbologia da casa, afirmando que o contrário também é verdadeiro: "o contrário significa, aqui, que entrar na casa é também entrar numa outra forma de mundo - ou melhor, numa outra dimensão de mundo, numa outra escala" (Ibidem:27). É nesta outra dimensão que tenta mergulhar Ludo, artificialmente reconstruindo sua própria casanação, ou seu casulo. Entremeada à narrativa de Ludo, 
surgem excertos de um diário, escrito pela personagem, momentos raros em que ela despe-se de suas couraças. Nestas escritas, Ludo quebra as paredes:

Sinto medo do que está para além das janelas, do ar que entra às golfadas, e dos ruídos que traz. (...) Sou estrangeira a tudo, como uma ave caída na correnteza de um rio. Não compreendo as línguas que me chegam lá de fora (...), nem sequer quando parecem falar português, porque este português que falam já não é o meu (37).

Zygmunt Bauman (2003), em Comunidade, discorre sobre esse lugar idílico em que os indivíduos sentemse sintonizados, quando pertencentes a um mesmo grupo, a um mesmo ideal, mas muitas vezes às custas da perda da liberdade de expressão, da homogeneização do pensamento, da massificação do comportamento. Compartilhar de uma mesma nacionalidade, sentirse em comunidade, ou melhor, partilhar de um mesmo sentimento de nação, segundo Bauman, é o resultado de um poderoso instrumento de mobilização ideológica, no qual, a partir da busca de raízes comuns, se é capaz de produzir uma lealdade e uma obediência patrióticas. Com relação a Ludo, enquanto participante da outra ponta da história, a do colonizador, nunca se sentiu irmanada em Angola. Nunca compartilhou dessa aliança com o outro, o angolano. Nunca se esforçou para tentar entender o outro. Nunca sequer olhou para o outro. Seu vínculo é com o passado, com aquilo que deixou em Aveiro. Sua conexão, portanto, é com a distância do que foi.

O tempo passa, desacelerado. Ludo vai sobrevivendo com criatividade à sua solidão, já que carregava com ela a certeza da irrelevância de sua existência: 'não havia ninguém, em qualquer lugar do mundo, aguardando por ela' (43). Pescava galinhas, e assim criou uma granja, brincava com cães, via hipopótamos. Os dias eram todos iguais: "entardecia, amanhecia, e era o mesmo vazio sem princípio ou fim" (45). Escutar estações de rádio era um pequeno passatempo, mas a portuguesa incomodava-se com as acusações contra o seu país: "Escutava também as estações angolanas, mesmo se irritavam os constantes discursos contra o colonialismo e as forças de reação" (42). Com o fim da energia elétrica, termina a possibilidade da transmissão das rádios, termina o contato definitivo de Ludo com o mundo externo. Ludo está, mais do que nunca, clandestina. "Uma manhã, levantou-se, e abriu uma torneira e a água não jorrou. Assustou-se. Ocorreulhe pela primeira vez que poderia permanecer longos anos encerrada no apartamento" (41). E assim foi.

Enquanto isso, Angola vivencia um processo forte de transformação. A chegada das tropas vindas de Cuba faz aumentar os conflitos. Há aqueles que são contrários a essa situação, como Jeremias, o Carrasco, personagem com breve participação na obra de Agualusa: "Eu fiquei em Angola por convicções. Combato pela civilização ocidental, contra o imperialismo soviético. Combato pela sobrevivência de Portugal" (33). Outro personagem, Papy Bolingô, é testemunha da violência: "Assistiu, depois, à chegada dos soldados cubanos, os quais colocaram rapidamente ordem na casa, à bofetada e ao pontapé, retomando o controlo da emissão" (89). E há aqueles, ainda, que condenam, por princípio, a luta do angolano contra o angolano: "Não foi para isso que fizemos a independência. Não para que os angolanos se matassem uns aos outros como cães raivosos" (71).

O confinamento de Ludo no apartamento, alienada do processo de construção do novo país que se dá lá fora, provoca igualmente um gradativo apagamento de sua identidade. Embora ainda possuísse mantimentos da época em que vivia com os familiares, Ludo vai apequenando-se física e psicologicamente. Desacostuma-se por completo da existência do outro, que lhe chega apenas a partir de sons e imagens opacas dos apartamentos vizinhos, agora invadidos por gente de todos os lugares: "Nos primeiros meses de isolamento, Ludo raramente dispensava a segurança do guarda-chuva para visitar o terraço. Mais tarde, passou a servir-se de uma comprida caixa de cartão, na qual recortara dois orifícios, à altura dos olhos, para espreitar" (75). Vista de cima, a imagem de uma caixa de papelão em movimento desafiava a lógica. Ludo começa a espiar o mundo lá fora. De tão acostumada a não viver, a não olhar, começa a perder, gradativamente, a visão. A redescoberta da curiosidade pelo mundo outro faz com que desafie os furos feitos na caixa para fotografar uma realidade da qual não faz parte: "Vez por outra, debruçava-se sobre o terraço, estudando, com rancor, a cidade submersa" (75). Ludo deixa de ver quando tenta enxergar o que lá fora se esconde. Acaba por perceber-se como aquela caixa de papelão, objeto sem importância esquecido no canto de um apartamento.

Há um acelerado avanço temporal na narrativa, resumido pelo narrador:

Rolaram anos. Caíram muros. Veio a paz, realizaram-se eleições, a guerra regressou. O sistema socialista foi desmantelado, pelas mesmas pessoas que o haviam erguido, e o capitalismo ressurgiu das cinzas, mais feroz do que nunca. Sujeitos que, havia poucos meses, bramiam em almoços de família, em festas, em comícios, em artigos nos jornais, contra a democracia burguesa, passeavam-se agora muito bem vestidos, com roupas de marca, dentro de veículos refulgentes (91).

E alheia a toda essa transformação, porém cada vez mais deteriorada, está a portuguesa de Aveiro. Ludo retorna a um mundo individual, primitivo, e até mesmo 
a sua sombra lhe causa susto, ao mesmo tempo em que projeta, qual cinema, uma cena epifânica: "Subitamente um grande clarão iluminou tudo, e a mulher viu a própria sombra a ser atirada contra a parede. O trovão ribombou um segundo depois. Se morresse ali, assim, naquele lúcido instante, enquanto lá fora o céu bailava, vitorioso e livre, isso seria bom" (77). Em seguida, porém, a dolorosa constatação de que já não existia. De que não era: "Decorreriam décadas antes que alguém a encontrasse. Pensou em Aveiro e compreendeu que deixara de se sentir portuguesa. Não pertencia a lado nenhum" (77).

Contudo, não há desespero na averiguação: apenas silêncio. A percepção de sua efemeridade ao mesmo tempo confere-lhe a sensação de despertencimento. Já não trazia o orgulho de ser portuguesa. Já não ostentava a arrogância de ser branca e europeia, simplesmente porque Ludo já não era nada. Ludo já não se sentia parte integrante da nação colonizadora, esses homens que se "orgulham (de fato se definem por isso) de ter sido desde sempre o que são, pelo menos desde o antigo ato da miraculosa criação realizada pelo herói fundador da nação" (BAUMAN, 2003:87), diz Bauman, e portanto, "até mesmo o mais zeloso e diligente dos assimilados voluntários carrega consigo na 'comunidade de destino' a marca de suas origens alienígenas, estigma que nenhum juramento de lealdade pode apagar" (Ibidem:87). Ludo, em contrapartida, mesmo em terra estrangeira, carregou a marca de sua lusitanidade, mas tanto a marca como ela própria foram apagadas.

Ausente de qualquer traço de comunidade, Ludo sofre um processo de objetificação, um apagamento gradual de seus contornos identitários. Assim como o seu país: "neste país tudo desaparece. Talvez o país inteiro esteja em vias de desaparecimento, uma aldeia aqui, outra acolá, quando dermos por isso não existe nada" (107). Para não se apagar por completo, Ludo ganha uma nova obsessão, a escrita: "Os dias deslizam como se fossem líquidos. Não tenho mais cadernos onde escrever. Também não tenho mais canetas. Escrevo nas paredes, com pedaços de carvão, versos sucintos" (81).

Ludo escreve e escreve-se, a desafiar o esquecimento. Mesmo com o fim do carvão, mesmo com o fim da parede, o processo mantém-se:

se ainda tivesse espaço, carvão, e paredes disponíveis, poderia escrever uma teoria geral do esquecimento. Dou-me conta de que transformei o apartamento inteiro num imenso livro. Depois de queimar a biblioteca, depois de eu morrer, ficará só a minha voz. Nesta casa, todas as paredes têm a minha boca (100).

Passa, pois, a habitar esse livro gigantesco, sua história paralela. Nem mesmo a morte parece percebê-la: "A morte gira ao meu redor, mostra os dentes, rosna.
Ajoelho-me e ofereço-lhe a garganta nua. Vem, vem, vem agora, amiga. Morde. Deixa-me partir. Ah, hoje vieste e esqueceste-te de mim" (116). E é quando quase mais nada lhe resta que Ludo começa a compreender-se angolana. A inversão do processo nasce junto a uma obra de arte: um quadro que havia em sua sala, sempre odiado por ela, porque trazia todo um contentamento, uma alegria de viver dos nativos que era quase ofensivo ao modo reservado e escondido da personagem:

$\mathrm{Na}$ parede da sala de visitas estava pendurada uma aguarela representando um grupo de mucubais a dançar. Ludo conhecera o artista (...) Ao princípio, odiou o quadro. Via nele um resumo de tudo o que a horrorizava em Angola: Selvagens celebrando algo - uma alegria, um augúrio feliz - que lhe era alheio (127).

Mas aos poucos, aquele retrato, o único elo que a mantinha com uma representação de um mundo outro, do lado de lá, começa a fazer parte dela. Como se ela entrasse nele. Como se ele fosse ela: "Depois, pouco a pouco, ao longo dos compridos meses de silêncio e de solidão, começou a ganhar afeto por aquelas figuras que se moviam, em redor de uma fogueira, como se a vida merecesse tanta elegância" (127). Sem luz, sem água, volta a um mundo rudimentar. Queima o que há no apartamento, mulher das cavernas, mas nunca aquele quadro:

Queimou as mobílias, queimou milhares de livros, queimou todas as telas. Foi só quando se viu desesperada que retirou os mucubais da parede. Ia para arrancar o prego (...) quando the ocorreu que talvez aquilo, aquele pedaço de metal, segurasse a parede. Talvez sustentasse todo o edifício. Quem sabe, arrancando o prego da parede, ruísse a cidade inteira (127).

Aquele quadro é a sua aproximação com o mundo esquecido, assim como ela. Aquele quadro é a sua casa. Aquele quadro é o seu mundo. Helena Buescu afirma que a casa reencena o mundo externo, e "dentro da casa, o homem não pode deixar de ser ator, por muito que queira ser (e mesmo que parcialmente seja) espectador" (BUESCU, 1999:27). Ludo percebe-se menos espectadora e mais integrante desse mundo. A permanência dessa aquarela, intacta, anuncia, simbolicamente, o surgimento de uma vida inimaginada, na chegada de alguém que mudaria o seu destino: Sabalu. O menino invade o apartamento da senhora, para roubar, e assusta-se com o que vê: "subiu até o terraço. Viu as galinhas mortas. Desceu e descobriu um apartamento depredado até ao osso, sem móveis, sem portas ou soalho. As paredes, cobertas de inscrições e estranhos desenhos, assustaram-no" (165). A invasão a 
esse mundo não definido pelo tempo histórico comove o menino, que de caçador passa a oferecer a caça, deixando comida para a estranha senhora. O pão é festejado. E nasce, entre ambos, um sentimento de partilha. Nasce uma família. O menino não tem ninguém, apenas a malícia das ruas. Chama-a por avó, e recebe um carinho que nem Ludo sabia-se capaz:

Tu ainda és uma criança.

Não consigo, avó. Como posso ser criança longe das mãos da minha mãe?

Eu dou-te as minhas.

Ludo não abraçava ninguém há muito tempo. Perdera um pouco a prática. Sabalu teve de lhe erguer os braços. Foi ele mesmo fazendo ninho no colo da velha senhora (161).

A cena, de contornos afetivos raros para uma mulher exilada do mundo, dá à velha senhora a certeza que faltava de estar em casa. Ensina-lhe os segredos da escrita, para que o jovem possa ler em voz alta para ela. Já não haveria, pois, necessidade do silêncio.

É quando surge uma filha a procurá-la, fruto de um estupro violento, ocorrido há décadas em Aveiro, que Ludo tem certeza do que não é. A mulher estranha avisa: "Não vim a Luanda para cobrar nada. Vim para a conhecer. Quero levá-la de volta para a nossa terra" (208). A nossa terra já não mais:

Ludo segurou-lhe a mão: Filha, esta é a minha terra. Já não me resta outra. Apontou para a mulemba: Tenho visto crescer aquela árvore. Ela viu-me envelhecer a mim. Conversamos muito.

A senhora há de ter família em Aveiro.

Família?! (...) A minha família é esse menino, a mulemba lá fora, o fantasma de um cão (208).

Ao dar-se conta da sua integração com a natureza do pouco que via, Ludo percebe-se nas coisas ao seu redor, em simbiose com aquele espaço. E assim, como afirma Inocência Mata no artigo "A natureza e o núcleo simbólico da Nação na literatura angolana", ocorre a contaminação entre terra e pátria. O sentido do nacional faz-se "através da celebração da realidade física (geografia, paisagens, flora, fauna) cósmica e quotidiana do país, transfigurando-a". (MATA, 1997:305). A mesma lógica desta relação mágica e associativa entre terra e nação é trazida por Manuel Ferreira, que salienta a restauração do Ser a partir da restauração do Espaço:

O espaço profanado pelo outro, pelo colonizador, é uma realidade evidente na agressão, na repressão, na destruição do Ser. O Caos está implantado. Mas os sintomas da reabilitação do Ser, da recons- trução do espaço sagrado (Luanda=Angola), começam a desenhar-se. Desenvolvem-se as condições para a apreensão e consciencialização das profundas contradições de uma sociedade colonialista (FERREIRA, 2007:131).

É este o processo pelo qual a personagem passa. Ludo reconstrói-se junto de Luanda. Ludo vê-se na árvore. Vê-se em Sabalu. Vê-se em Angola, num procedimento que vem da desarmonia à harmonia. Diz Mata: "A grande mudança percebe-se no tratamento da Terra: esta já não é espaço cênico do idílio do homem com a natureza, mas interlocutor na verberação de uma situação indigna da terra" (MATA, 1997:306). A Angola percebida por Ludo entre as frestas de sua caixa de papelão era um espaço perturbador, de ebulição, de destruição, mas também de reconstrução.

O menino igualmente agarra-se na senhora com o alívio de quem encontra um próximo. E com a responsabilidade de quem cuida de um ser frágil. Quando começa a derrubar a parede no corredor, o muro que isolava Ludo de Luanda, um vizinho indaga quem ele é. Apagando um passado de perdas mútuas, Sabalu responde que mora ali, desde sempre, com a sua avó. E quando dialoga com Ludo, antes da simbólica destruição, promete protegê-la contra o que existe ali atrás: o mundo.

Stuart Hall, no texto Da diáspora: Identidade e mediações culturais, postula a estreita relação entre a 'questão multicultural e o fenômeno do pós-colonial', especialmente por perceber que a problemática deste último ainda não foi, de modo algum, resolvida: os conflitos vividos durante o colonialismo persistem no depois. Se havia a desigualdade e a exploração num passado imperialista, nos dias atuais essas mesmas relações são reencenadas. Na referida obra, o teórico jamaicano cita a problemática das ex-colônias, colocando a questão do imperialismo como entrave para o seu desenvolvimento: "Pensemos que [...] os contínuos problemas de legitimidade e estabilidade política no Afeganistão, Namíbia, Moçambique ou Angola têm origens claras em sua recente história imperial" (HALL, 2009:54).

Vivendo na carne e na ausência o processo de descolonização, foi com a reescrita de si mesma que Ludo (re)descobriu-se. Manuel Ferreira poetiza: "O Cosmo se reorganizou. Angola é espaço sagrado. Espaço libertado" (FERREIRA, 2007:131). É com a Angola livre que Ludo também liberta-se. Foi com a escrita que sobreviveu. Com a escrita e com a criança: duas promessas de futuro. E na escritura de si própria, uma reconciliação entre Ludo e aquela que foi:

Para quem escrevo? Escrevo para quem fui. Talvez 
aquela que deixei um dia persista ainda, em pé e parada e fúnebre, num desvão do tempo - numa curva, numa encruzilhada - e de alguma forma misteriosa consiga ler as linhas que aqui vou traçando, sem as ver. Ludo, querida: sou feliz agora (231).

Ao fechar-se, ao isolar-se, abriu-se para uma Ludo desconhecida: "Teria sido tão fácil abrires a porta, tão fácil saíres para a rua e abraçares a vida. Vejo-te espreitar pelas janelas, aterrorizada, como uma criança que se debruça sobre a cama, na expectativa de monstros" (231). Ludo fechou as portas, mas escolheu ficar. E nessa escolha, a opção de finalmente fincar raízes. De voltar a existir, de voltar a ser. Ludo exorcizou seus fantasmas, seus monstros: "Monstros, mostra-me os monstros: essas pessoas nas ruas. A minha gente" (231).

E agora, vencido o próprio esquecimento, Ludo já consegue olhar para o céu. Já não precisa de guardachuva ou caixa de papelão: "Saio à rua e já não sinto vergonha. Não sinto medo. Saio à rua e as quitandeiras cumprimentam-me. Riem-se para mim como parentes próximas". (227) Apaziguada com o passado, passeia por uma Luanda sua, já sorri e também volta a brincar: "As crianças brincam comigo, dão-me a mão. Não sei se por eu ser muito velha, se por eu ser tão criança quanto elas" (227).

Ludo, lúdica, desconstruída, reconstruída, sabe que é nos sonhos que tudo começa. E no sonho, "Ludo era uma menina. Estava sentada numa praia de areia branca. Sabalu, estendido de costas, com a cabeça pousada no seu regaço, olhava o mar. Falavam do passado e do futuro. Trocavam recordações" (235).

E riam.

\section{Referências}

AGUALUSA, José Eduardo. Teoria geral do esquecimento. Lisboa: D. Quixote, 2012.

ANDERSON, Benedict. Comunidades imaginadas. São Paulo: Companhia das Letras, 2008.

BAUMAN, Zygmunt. Comunidade: a busca por segurança no mundo atual. Rio de Janeiro: Jorge Zahar Ed., 2003.

BUESCU, Helena Carvalhão. A casa e a encenação do mundo. In: SILVEIRA, Jorge (Org.). Escrever a casa portuguesa. Belo Horizonte: UFMG, 1999.

FERREIRA, José Medeiros. Portugal em transe. In: MATTOSO, José (Dir.). História de Portugal. Lisboa: Estampa, 2001.

FERREIRA, Manuel. Do caos se fez espaço sagrado=libertado. In: VIEIRA, José Luandino. A cidade e a infância. São Paulo: Companhia das Letras, 2007.

GARCIA, Rita. S.O.S. Angola: os dias de ponte aérea. Alfragide: Oficina do Livro, 2011

HALL, Stuart. Da diáspora: identidades e mediações culturais. Belo Horizonte: UFMG, 2009.

LOURENÇO, Eduardo. O labirinto da saudade. Lisboa: Gradiva, 2001.

LOURENÇO, Eduardo. A nau de Ícaro e imagem e miragem da lusofonia. São Paulo: Companhia das Letras, 2001b.

MATA, Inocência. A natureza e o núcleo simbólico da Nação na literatura angolana. In: CRISTÓVÃO, Fernando; FERRAZ, Maria de Lurdes; CARVALHO, Alberto. Nacionalismo e regionalismo nas literaturas lusófonas. Lisboa: Cosmos, 1997.

WHEELER, Douglas; PÉLISSIER, René. História de Angola. Lisboa: Tinta da China, 2013.

Recebido: 10 de novembro de 2014 Aprovado: 09 de janeiro de 2015 Contato: paulokralik@gmail.com 